\title{
Efektifitas Pemanfaatan Media Gambar Bergerak dan Video Animasi terhadap Peningkatan Pengetahuan dan Sikap Ibu tentang Gizi Seimbang pada Balita
}

\author{
Christin Angelina $\mathbf{F}^{1}$, Dina Dwi Nuryani ${ }^{2}$, Dessy Elviyanti ${ }^{3}$ \\ Fakultas Kesehatan Masyarakat, Universitas Malahayati Bandar Lampung, Indonesia \\ Email: angelina@malahayati.ac.id/christin.angelinaf@gmail.com
}

\begin{abstract}
The Effectiveness of Moving Picture and Animated Video Media to Knowledge and Attitude Improvement of Mothers Concerning Balanced Nutrition for Children Under Five. The fact that malnutrition occurs during the golden age is irreversible, so more attention is needed in the growth and development of toddler age. This research is aim to find out the improvements of mothers' knowledge concerning balanced nutrition for children under five before and after intervention by using moving picture and animated video media in Ambarawa public health center working area in Pringsewu district in 2019. Quantitative-quasi-experiment design, with pretest-post-test with the group design approach. The population was 216 respondents and 40 respondents were taken by using proportional random sampling and purposive sampling. Data were analyzed with univariate and bivariate analyses by using the independent t-test. The results showed that the averages of mothers' knowledge concerning balanced nutrition for children under five before and after using moving picture media intervention were 78.60 and 83.80 , and before and after using animated video media intervention were 78.00 and 91.90 with p-value 0.120 . The averages of mothers attitude concerning balanced nutrition for children under five before and after using moving picture media intervention were 76.05 and 78.60 , and before and after using animated video media intervention were 78.55 and 85.65 with p-value 0.087 . Animation media is more effective against increasing the knowledge and attitudes of mothers about balanced nutrition, it appears from the average value of the use of animation media higher than moving images.
\end{abstract}

Keywords: Animation, Attitude, Balanced nutrition for children under five, Knowledge, Moving picture media

\begin{abstract}
Abstrak: Efektifitas Pemanfaatan Media Gambar Bergerak dan Video Animasi terhadap Peningkatan Pengetahuan dan Sikap Ibu tentang Gizi Seimbang pada Balita. Fakta bahwa kurang gizi terjadi pada masa emas bersifat irreversible, maka dibutuhkan perhatian lebih dalam tumbuh kembang usia balita. Tujuan penelitian diketahuinya peningkatan pengetahuan dan sikap ibu tentang gizi seimbang pada balita sebelum dan sesudah diberikan intervensi menggunakan media gambar bergerak dan video animasi di Wilayah UPT Kerja Puskesmas Ambarawa Kabupaten Pringsewu Tahun 2019. Jenis penelitian kuantitatif, desain penelitian quasi eksperiment dengan pendekatan pre test-post test with group design. Populasi berjumlah 216 orang, pengambilan sampel menggunakan proportional random sampling sebanyak 40 responden kemudian dilakukan teknik purposive sampling. Analisis data secara univariat dan bivariat dengan uji T-Independent. Hasil penelitian menunjukkan rerata pengetahuan ibu tentang gizi seimbang pada balita menggunakan media gambar bergerak sebelum intervensi $(78,60)$, sesudah intervensi $(83,80)$; media animasi, sebelum intervensi $(78,00)$, sesudah intervensi $(91,90)$ p-value 0,120 . Hasil untuk rerata sikap dengan media gambar bergerak sebelum intervensi $(76,05)$, sesudah intervensi $(78,60)$; media animasi, sebelum intervensi $(78,55)$ dan sesudah intervensi $(85,65) p$ value 0,087 . Media animasi lebih efektif terhadap peningkatan pengetahuan dan sikap ibu tentang gizi seimbang, tampak dari nilai mean penggunaan media animasi lebih tinggi dibandingkan gambar bergerak.
\end{abstract}

Kata kunci: Animasi, Sikap, Gizi seimbang balita, Pengetahuan, Media gambar bergerak

\section{PENDAHULUAN}

Balita adalah anak usia 1-5 tahun yang masih dalam tahap pertumbuhan dan perkembangannya yang ditandai dengan aktifitas anak untuk belajar berbicara, lari dan mulai bersosialisasi. Pada masa balita tentunya masih memerlukan perhatian khusus dari orang tua, 
perkembangan ini merupakan hasil interaksi antara keadaan lingkungan, fisik dan psikis yang menimbulkan tampilan dan kualitas tumbuh kembang anak (Istiany \& Rusilanti, 2013). Gizi seimbang di dalamnya memiliki keterkaitan yang erat dengan kesehatan dan kecerdasan, gizi merupakan salah satu penentu kualitas sumber daya manusia (Hardiansyah, M. S., \& Supariasa, I. D, 2017). Masa balita adalah periode perkembangan fisik dan mental yang pesat. Pada masa ini otak balita telah siap menghadapi berbagai stimuli seperti belajar berjalan dan berbicara lebih lancar. Perlunya perhatian lebih dalam tumbuh kembang di usia balita didasarkan fakta bahwa kurang gizi yang terjadi pada masa emas ini, bersifat irreversible (tidak dapat pulih) (Irianto, 2014).

Berdasarkan data Pemantauan Status Gizi (Irnani, H \& Sinaga, T. (2017) di Indonesia dengan status gizi kurang sebesar $(14,0 \%)$ dan gizi buruk sebesar $(3,8 \%)$, dimana provinsi tertinggi adalah Nusa Tenggara Timur sebesar $(7,4 \%)$, diikuti Papua sebesar $(6,8 \%)$ dan Papua Barat sebesar $(6,6 \%)$. Provinsi Lampung sendiri merupakan wilayah dengan masalah gizi akut, diketahui angka gizi kurang mengalami peningkatan dari tahun 2016 sebesar $(12,4 \%)$ menjadi $(15,0 \%)$ di tahun 2017 , begitu pula dengan angka gizi buruk, dari $(1,6 \%)$ pada tahun 2016, meningkat menjadi $(3,5 \%)$ di tahun 2017 (Direktorat Gizi Masyarakat \& Direktorat Jenderal Kesehatan Masyarakat). Tren kasus gizi buruk di provinsi Lampung tahun 2011-2016 berfluktuatif, tahun 2011 sebesar 255 kasus, di tahun 2012 menjadi 203, di tahun 2013 berjumlah 154 kasus, tahun 2014 jumlah gizi buruk sebanyak 136 kasus, di tahun 2015 kasus gizi buruk sebanyak 136 kasus, dan di tahun 2016 jumlah kasus gizi buruk menurun menjadi 99 kasus (Dinas Kesehatan Propinsi Lampung, 2016). Prevalensi gizi kurang terbesar terdapat di Lampung Tengah (19,6\%), Lampung Utara $(17,8 \%)$, Mesuji $(17,1 \%)$, Bandar Lampung $(16,8 \%)$, Pesawaran $(13,6 \%)$, kabupaten Pringsewu $(12,4 \%)$. Sedangkan untuk gizi buruk prevalensi tertinggi ada di kabupaten Pringsewu sebesar (5\%) dimana prevalensi yang sama terdapat di Kota Bandar Lampung, diikuti Pesawaran sebesar (4,5\%), Tulang Bawang Barat sebesar $(4,3 \%)$ dan Tanggamus sebesar (4\%) (Kementerian Kesehatan, 2017). Berdasarkan data Pemantauan Status Gizi 2016 dan 2017, angka gizi kurang pada balita di Kabupaten Pringsewu masuk dalam kategori 6 besar gizi buruk di Lampung, data gizi buruk ditahun 2016 yaitu sebesar (14,2\%), dan di tahun 2017 prevalensi gizi buruk yaitu $(12,4 \%)$ (Dinas
Kesehatan Pringsewu, 2016). Laporan LB3 Gizi Dinas Kesehatan Kabupaten Pringsewu tahun 2017 bahwa di Wilayah Kerja Puskesmas Ambarawa memiliki angka gizi kurang tertinggi dari seluruh Puskesmas yang ada di Kabupaten Pringsewu dengan prevalensi gizi kurang sebesar $(14,1 \%)$ dan gizi buruknya terdapat 2 kasus (Dinas Kesehatan Pringsewu, 2017).

Kejadian masalah gizi pada balita ini dapat dihindari apabila ibu memiliki pengetahuan dan sikap yang baik mengenai cara pemberian makanan dan mengatur makanan balita dengan baik. Pendidikan gizi pada hakikatnya adalah suatu kegiatan atau usaha menyampaikan pesan gizi kepada masyarakat, kelompok, atau individu dengan harapan agar bisa memperoleh pengetahuan dan sikap tentang gizi seimbang yang lebih baik sehinga dapat berpengaruh pada sikap dan perilaku (Notoatmodjo, 2012). Agar masyarakat mampu berperan aktif seperti yang diharapkan, maka diperlukan masyarakat yang memiliki pengetahuan cukup dalam bidang kesehatan, dan memiliki sikap yang positif terhadap kesehatan serta mempunyai kemauan dan kemampuan dalam melaksanakan upayaupaya kesehatan secara mandiri (Suiraoka, I. P., $\&$ Supariasa, I. D. N, 2012). Perilaku yang positif dapat dibentuk dari pengetahuan yang baik, sehingga cara yang tepat untuk meningkatkan pengetahuan adalah dengan menggunakan media sebagai pendidikan kesehatan (Ma'munah, M, 2015). Pendidikan gizi tidak dapat lepas dari media karena melalui media, pesan-pesan yang disampaikan dapat lebih menarik dan dipahami, sehingga sasaran dapat mempelajari pesan tersebut sampai memutuskan untuk mengadopsi prilaku yang positif (Maulana, 2009). Berdasarkan hasil pre survei yang dilakukan oleh peneliti terhadap 10 orang ibu-ibu yang memiliki anak balita di wilayah kerja UPT Puskesmas Ambarawa diperoleh 8 orang (80\%) ibu kurang mengetahui tentang gizi seimbang dan sikap ibu dalam mengonsumsi aneka ragam makanan dan buah-buahan setiap minggu nya masih jarang dilakukan. Peneliti berasumsi meskipun ibu-ibu pernah mendapatkan sosialisasi tentang gizi seimbang, akan tetapi mayoritas pengetahuan dan sikap ibu masih kurang baik, hal ini disebabkan karena penyuluhan yang dilakukan oleh tenaga kesehatan hanya dengan menggunakan metode ceramah saja, tidak menggunakan media atau metode lain yang bervariasi dalam penyampaian pesan gizi seimbang. 


\section{METODE}

Jenis penelitian yang digunakan yaitu penelitian kuantitatif, rancangan penelitian adalah Quasi Eksperimen dengan pendekatan pre test-post test with group design. Populasi dalam penelitian ini adalah seluruh ibu yang memiliki balita (1-5 tahun) di Pekon Margodadi Wilayah Kerja UPT Puskesmas Ambarawa Kabupaten Pringsewu sejumlah 216 ibu yang memiliki anak balita dengan jumlah sampel $40 \mathrm{ibu}$ yang memiliki anak balita. Tehnik pengambilan sampel yaitu dengan proportional random sampling, Analisis hubungan yang digunakan adalah uji $t$ test independent dengan taraf signifikan 5\%.

Penelitian ini telah mendapatkan persetujuan etik penelitian (ecthical clearance) dari Komisi Etik Penelitian Kesehatan Universitas Malahayati No. 32/EC/KEPUNMAL/I/2019.

\section{HASIL}

Tabel 1. Perbedaan Pengetahuan dan Sikap Ibu Tentang Gizi Seimbang Pada Balita Sebelum dan Sesudah Pemberian Media Gambar Bergerak

\begin{tabular}{lcccrc}
\hline \multicolumn{1}{c}{ Variabel } & Mean & SD & $\begin{array}{c}\Delta \\
\text { Mean }\end{array}$ & $\begin{array}{c}\mathbf{9 5 \%} \\
\text { CI }\end{array}$ & $\begin{array}{c}\boldsymbol{p} \text { - } \\
\text { value }\end{array}$ \\
\hline $\begin{array}{l}\text { Pengetahuan } \\
\text { Sebelum }\end{array}$ & 78,60 & 9,29 & & & \\
Sesudah & 83,80 & 7,16 & 5,20 & $3,00-$ & 0,000 \\
\hline Sikap & & & & & \\
Sebelum & 76,05 & 3,57 & 2,55 & $0,70-$ & 0,002 \\
Sesudah & 78,60 & 2,99 & & 1,06 & \\
\hline
\end{tabular}

Tabel 2. Perbedaan Pengetahuan dan Sikap Ibu tentang Gizi Seimbang pada Balita Sebelum dan Sesudah Pemberian Media Animasi

\begin{tabular}{lccccc}
\hline \multicolumn{1}{c}{ Variabel } & Mean & SD & $\begin{array}{c}\Delta \\
\text { Mean }\end{array}$ & $\begin{array}{c}\mathbf{9 5 \%} \\
\text { CI }\end{array}$ & $\begin{array}{c}\boldsymbol{p} \text { - } \\
\text { value }\end{array}$ \\
\hline $\begin{array}{l}\text { Pengetahuan } \\
\text { Sebelum }\end{array}$ & 78,00 & 8,55 & & & \\
Sesudah & 91,40 & 4,54 & 13,40 & $1,33-$ & 0,000 \\
\hline $\begin{array}{l}\text { Sikap } \\
\text { Sebelum }\end{array}$ & 78,55 & 4,74 & & & \\
Sesudah & 85,65 & 3,85 & 7,10 & $5,16-$ & 0,000 \\
\hline
\end{tabular}

Responden pada pre test kelompok media gambar bergerak diketahui skor pengetahuan sebelum diberikan intervensi yaitu sebesar 78,60, untuk kelompok media animasi skor pengetahuan pre test yaitu sebesar 78,00.

Kelompok media gambar bergerak saat pre test rata-rata sikap responden yaitu 76,05 dan saat post test terjadi perubahan sikap menjadi 78,60. Kelompok media animasi pada saat pre test yaitu 78,55 dan post test terdapat perubahan sikap sebesar 85,65.

Perubahan pengetahuan menggunakan media gambar bergerak 5,20 dan perubahan pengetahuan dengan pemberian media animasi sebesar 13,40. Sedangkan perubahan sikap menggunakan media gambar bergerak 2,55 dan perubahan pengetahuan dengan pemberian media animasi sebesar 7,10

Tabel 3. Efektifitas Pemberian Media Gambar Bergerak dan Media Animasi terhadap Pengetahuan dan Sikap Ibu Tentang Gizi Seimbang pada Balita

\begin{tabular}{lcccc}
\hline \multicolumn{1}{c}{ Selisih } & n & $\begin{array}{c}\Delta \\
\text { Mean }\end{array}$ & SD & $\begin{array}{c}\boldsymbol{p} \text { - } \\
\text { value }\end{array}$ \\
\hline Pengetahuan & & & & \\
Gambar Bergerak & 20 & 5,20 & 4,697 & 0,000 \\
Animasi & 20 & 13,40 & 5,986 & \\
\hline Sikap & & & & \\
Gambar Bergerak & 20 & 2,55 & 3,170 & 0,000 \\
Animasi & 20 & 7,10 & 4,141 & \\
\hline
\end{tabular}

\section{PEMBAHASAN}

\section{Pengetahuan Responden Tentang Gizi Seimbang pada Balita}

Hasil penelitian sebelum intervensi dari dua kelompok ini menunjukkan bahwa pengetahuan ibu tentang gizi seimbang sudah baik tetapi masih ada beberapa ibu dalam pengetahuan mengenai pedoman gizi seimbang masih belum cukup baik karena masih ada ibu yang belum mengetahui pesan dalam pedoman umum gizi seimbang, jenis konsumsi pangan setiap kali makan, peran vitamin, dan mineral, porsi konsumsi sayuran dan buah-buahan. Hal ini terjadi bukan hanya faktor-faktor dari ibu saja tetapi dari pihak puskesmas dan kader posyandu yang kurang memberikan informasi tentang gizi yang berkelanjutan, kebanyakan pihak puskesmas hanya memberikan pemberian makanan tambahan (PMT) dan ibu mendapatkan penyuluhan mengenai gizi seimbang dari pihak puskesmas yaitu hanya dengan metode ceramah saja penyuluhan tersebut juga jarang dilakukan sehingga ibu lebih dominan hanya mendengarkan materi yang disampaikan dan hal ini menyebabkan ibu tidak memiliki contoh objek hasil belajar secara langsung sehingga ibu tidak mudah untuk mengingat informasi yang didapatkan, sedangkan di Wilayah Kerja UPT Puskesmas Ambarawa Kabupaten Pringsewu 
belum pernah mendapatkan informasi maupun mendapatkan penyuluhan gizi seimbang pada balita melalui media gambar bergerak dan animasi, dengan kondisi ini sangat ini sangat memungkinkan responden lupa mengenai materi yang diberikan dan harus mengingat kembali saat dilakukan penelitian.

Setelah pemutaran media animasi tentang gizi seimbang pada balita dilakukan pengulasan kembali mengenai pengetahuan ibu dan beberapa ibu mampu menyampaikan kembali pengertian gizi seimbang, penyakit yang terjadi jika mengonsumsi makanan tinggi kadar gula, minyak dan garam, kerugian tidak sarapan pagi, anjuran konsumsi air minum perhari, fungsi cuci tangan pakai sabun, cara menjaga berat badan normal dan akibat dari makanan serta minuman yang kotor. Berdasarkan hasil pengulasan yang dilakukan terlihat dari responden kelompok media animasi diperkuat dari hasil post test terjadi peningkatan dimana hasil pre test sebesar 78,00 dan post test meningkat menjadi 91,40. Adanya informasi dengan media gambar bergerak dapat meningkatkan keinginan responden untuk memperhatikan informasi apa saja yang tersaji dalam tayangan gambar bergerak tersebut. Informasi yang ada di dalam media gambar bergerak kemudian diperjelas dengan terdapat tulisan di dalam gambar yang ditanyangkan sehingga responden dapat membaca dan memahami isi pesan yang ada di dalam media gambar, maka dapat meningkatkan pengetahuan responden. Pada kelompok media gambar bergerak juga terjadi peningkatan pengetahuan yaitu dari 78,60 menjadi 83,80 . Terjadinya peningkatan pengetahuan responden ini dimana responden dapat membaca dan melihat gambar yang ditayangkan sehingga dapat mempercepat daya ingat responden tentang gizi seimbang pada balita.

\section{Sikap Responden tentang Gizi Seimbang pada Balita}

Dari hasil tersebut dinyatakan bahwa pada hasil pre test responden sudah memiliki sikap yang baik dan positif tetapi ada beberapa responden masih memiliki sikap yang belum cukup positif dalam pemenuhan makanan yang beraneka ragam, pengolahan makanan yang belum baik, konsumsi air minum hanya pada saat haus, belum membiasakan membaca label pada kemasan pangan dan beranggapan bahwa bila berat badan anak normal artinya kebutuhan energi anak sudah tercukupi. Setelah responden diintervensi dan dilakukan pengukuran post test adanya perubahan sikap ibu menjadi lebih baik dan lebih positif lagi dalam pemenuhan pedoman gizi seimbang hal ini mencerminkan bahwa adanya media gambar bergerak dan animasi sebagai alat bantu dalam perubahan sikap responden membuktikan bahwa media sangat diperlukan agar sikap responden semakin baik dalam menilai dan bertindak lebih positif dalam pemenuhan gizi seimbang pada balita.

Sikap positif ditunjukkan responden setelah melihat tayangan media gambar bergerak ataupun media animasi tentang gizi seimbang memberi imbas terhadap persepsi positif dan tindakan ibu bahwa usia balita membutuhkan pemenuhan gizi yang baik karena berpengaruh terhadap pertumbuhan dan perkembangannya. Ibu termotivasi menerapkan pengolahan makanan yang lebih baik dan tidak berasumsi bahwa setiap mengolah makanan harus dibubuhkan garam, tidak mengonsumsi air minum hanya pada saat haus saja karena konsumsi air minum yang dianjurkan minimal 2 liter atau 8 gelas perhari dan membiasakan membaca keterangan label pada pangan yang dikemas. Adanya informasi dari media gambar bergerak dan animasi mengenai risiko yang terjadi apabila balita mengalami gizi kurang dan gizi buruk akan mempengaruhi sikap ibu terhadap dampak masalah gizi tersebut.

\section{Efektifitas Media Gambar Bergerak dan Media Animasi terhadap Peningkatan Pengetahuan dan Sikap Ibu tentang Gizi Seimbang pada Balita}

Terdapat perbedaan pengetahuan gizi seimbang pada balita sebelum dan sesudah pemberian media gambar bergerak dan pemberian media animasi di Wilayah Kerja UPT Puskesmas Ambarawa Kabupaten Pringsewu Tahun 2019 ( $p$-value 0,000). Sedangkan untuk hasil perubahan sikap menggunakan media gambar bergerak 2,55 dan perubahan sikap dengan pemberian media animasi sebesar 7,10. Terdapat perbedaan sikap gizi seimbang pada balita sebelum dan sesudah pemberian media gambar bergerak dan pemberian media animasi di Wilayah Kerja UPT Puskesmas Ambarawa Kabupaten Pringsewu Tahun 2019 ( $p$-value $0,000)$. Berdasarkan hasil penelitian menunjukkan bahwa media animasi lebih efektif terhadap peningkatan pengetahuan dan sikap ibu tentang gizi seimbang.

Pengetahuan merupakan hasil dari tahu, dan ini terjadi setelah orang melakukan penginderaan terhadap objek tertentu. Penginderaan terjadi melalui panca indra manusia yakni indra penglihatan, pendengaran penciuman, 
rasa dan raba. Sebagian besar pengetahuan manusia diperoleh melalui mata dan telinga. Pengetahuan atau kognitif merupakan dominan yang sangat penting untuk tindakan seseorang. Sedangkan sikap yaitu merupakan predisposisi perilaku (tindakan) atau reaksi tertutup. Dalam menentukan sikap yang utuh, pengetahuan, pikiran, keyakinan dan emosi memegang peranan penting dalam pengukuran sikap sehingga sulit diukur dan mudah berubah karena tergantung dari pengalaman pribadi, pengaruh orang lain yang dianggap penting, pengaruh kebudayaan, media massa, lembaga pendidikan dan lembaga agama serta faktor emosional dari sifat egois dari ibu itu sendiri.

Peneliti berpendapat terdapat perbedaan signifikan pengetahuan dan sikap ibu tentang gizi seimbang pada balita antara dua kelompok media tersebut disebabkan informasi tentang gizi melalui media animasi secara langsung menyebabkan responden memiliki objek materi yang dapat diamati terutama melalui panca indera pendengaran dan penglihatan. Pada saat responden memperhatikan penyampaian informasi yang peneliti berikan melalui media animasi tentang gizi seimbang maka terjadi proses transfer informasi yang menyebabkan kognitif pengetahuan responden pun lebih baik dibandingkan pada intervensi media gambar bergerak. Hal ini berdampak pada kemampuan responden menjawab pertanyaan pada kuesioner dengan baik. Begitu sebaliknya pada kelompok media gambar bergerak diketahui juga ada perubahan pengetahuan dan sikap. Adanya perubahan pengetahuan dan sikap dimana responden dapat melihat gambar yang hidup secara cepat dan bergantian sehingga memberikan visual yang kontinyu, dengan adanya gabungan potongan dua gambar atau lebih, membantu untuk kebutuhan terhadap gambar yang sesuai dengan tujuan pembelajaran akan dapat terpenuhi. Susilana, R., Si, M., \& Riyana, C. (2008), media gambar bersifat lebih konkret yaitu lebih realistis dapat menunjukkan masalah pokok dibandingkan dengan media verbal semata sehingga dapat melihat permasalahan yang disampaikan dalam pesan. Peneliti melihat bahwa responden pada kelompok media gambar bergerak lebih mudah dalam memahami apa yang disampaikan, proses pengajaran lebih menarik, ibu akan dirangsang untuk aktif mengamati tanpa adanya penjelasan secara rinci karena hanya menggunakan indra penglihatan. Namun dalam penelitian ini ternyata media gambar bergerak kurang efektif penerimaannya oleh responden, sehingga responden yang menggunakan media gambar bergerak mempunyai nilai pengetahuan dan sikap lebih rendah jika dibandingkan dengan menggunakan media animasi.

Oleh sebab itu, pentingnya media animasi dalam membantu peran petugas kesehatan sangat signifikan untuk meningkatkan pengetahuan dan sikap ibu tentang gizi seimbang dengan melibatkan indra penglihatan dan pendengaran responden secara langsung. Media ini dapat meningkatkan perhatian, konsentrasi dan imajinasi ibu kemudian ibu tersebut diharapkan mulai belajar menerapkan pedoman gizi seimbang, pengetahuan dan sikap yang baik didasari oleh pemahaman yang baik terhadap suatu materi yang dipelajari dan yang dipahami. Hal yang lain penting dilakukan pihak Puskesmas dan Dinas Kesehatan dapat mengaplikasikan media animasi atau media gambar bergerak sebagai suatu media baru dalam proses pembelajaran atau proses edukasi ke masyarakat sehingga memberikan modifikasi penyampaian pesan kesehatan mengenai gizi seimbang agar proses pemberian edukasi tidak monoton dan pesan yang disampaikan dapat diterima dengan baik.

\section{SIMPULAN}

Ada perbedaan peningkatan pengetahuan dan sikap ibu tentang gizi seimbang pada balita sebelum dan sesudah diberikan intervensi media gambar bergerak. Ada perbedaan peningkatan pengetahuan dan sikap ibu tentang gizi seimbang pada balita sebelum dan sesudah diberikan intervensi media video animasi. Media animasi lebih efektif terhadap peningkatan pengetahuan dan sikap ibu tentang gizi seimbang, tampak dari nilai mean penggunaan media animasi lebih tinggi dibandingkan gambar bergerak.

Kesehatan Dinas Kesehatan Kabupaten Pringsewu. Lampung.

Dinas Kesehatan Pringsewu. (2017). Profil Kesehatan Kabupaten Pringsewu Tahun 
2017. Pringsewu: Sistem Informasi Kesehatan Dinas Kesehatan Kabupaten Pringsewu. Lampung.

Dinas Kesehatan Propinsi Lampung. (2016). Profil Provinsi Lampung Tahun 2015. Bandar Lampung: Dinas Kesehatan Pemerintah Propinsi Lampung.

Direktorat Gizi Masyarakat \& Direktorat Jenderal Kesehatan Masyarakat. (2018). Buku Saku Pemantauan Status Gizi Tahun 2017. Jakarta: Direktorat Gizi Masyarakat, Direktorat Jenderal Kesehatan Masyarakat, Kementerian Kesehatan RI.

Hardiansyah, M. S., \& Supariasa, I. D. (2017). Ilmu gizi teori dan aplikasi. Jakarta: EGC.

Irianto, K. (2014). Gizi Seimbang dalam kesehatan reproduksi. Bandung: Alfabeta.

Irnani, H., \& Sinaga, T. (2017). Pengaruh pendidikan gizi terhadap pengetahuan, praktik gizi seimbang dan status gizi pada anak Sekolah Dasar. Jurnal Gizi Indonesia (The Indonesian Journal of Nutrition), 6(1), 58-64. https://doi.org/https://doi.org/10.14710/jgi. 6.1.58-64.
Istiany, A., \& Rusilanti. (2013). Gizi Terapan. Bandung: PT Remaja Rosdakarya

Kementerian Kesehatan. (2017). Buku Saku Pemantauan Status Gizi Tahun 2017. Jakarta. Kementerian Kesehatan.

Ma'munah, M. (2015). Pengaruh Pendidikan Kesehatan Dengan Booklet Terhadap Pengetahuan Ibu Laktasi Di Wilayah Kerja Puskesmas Ciputat Timur. (Skripsi, Program Studi Ilmu Keperawatan, Universitas Islam Negeri Syarif Hidayatullah). Jakarta.

Maulana, H. D., Sos, S., \& Kes, M. (2009). Promosi Kesehatan. EGC.

Notoatmodjo, S. (2012). Promosi Kesehatan dan Perilaku Kesehatan. Jakarta: Rineka Cipta.

Suiraoka, I. P., \& Supariasa, I. D. N. (2012). Media pendidikan kesehatan. Yogyakarta: Penerbit Graha Ilmu.

Susilana, R., Si, M., \& Riyana, C. (2008). Media pembelajaran: hakikat, pengembangan, pemanfaatan, dan penilaian. CV. Wacana Prima. 